\title{
Play and virtuality
}

\section{Svein Sando}

The similarities between virtuality and play are obvious, beginning with, for instance, the ubiquitous character of both. This paper deals with how insights from research on play can be used to enlighten our understanding of the ethical dimensions of activities in cyberspace, and vice versa. In particular, a central claim that play is beyond vice and virtue is debated and contested.

Keywords: play, virtuality, games, Huizinga, Bateson, Gadamer, virtual rape, ubiquity

\section{Introduction}

Those who examine the phenomena of play from a scientific point of view ought to deal with the classical work Homo Ludens, written in 1938 by the Dutch professor of culture and history, Johan Huizinga. Homo Ludens was translated into several languages and many editions and printings. An electronic version was published in 2000 and a Swedish printed edition as late as 2004. Huizinga's project is to put play in the centre of human culture, both as a part of the evolution of the culture and as something that concerns all humanity. Play is not a temporary activity performed by children only, but develops, according to Huizinga, into many forms in adult life as well. Huizinga writes that play is a mental action. For an ethicist, the following statement by Huizinga will be of interest: 'Although it [play] is a nonmaterial ${ }^{1}$ activity it has no moral function. The valuations of vice and virtue do not apply here' (Huizinga 1955: 6). The first impression of this claim is that play, or at least some important aspects of play, belongs to a non-ethical domain.

When I started to write this paper, the 'Gathering' was taking place in the Viking Ship Olympic Skating Arena at Hamar, Norway (www.gathering.org). Every Easter since 1996, approximately 5000, mainly young people have 
gathered for five days to play computer games. They gather in the large speedskating arena built for the 1994 Winter Olympic Games. Note the emphasis on the words 'play' and 'games'. Playing and games have become an increasingly important part of the culture in industrialized countries, partly due to more leisure time, and because a lot of these activities are performed through the use of computer technology. Concepts such as 'virtuality', 'virtual reality' and 'virtual worlds' are closely connected to this technology. The virtual, which may be defined as that which is not real but not completely unreal either, bears great resemblance to one of Huizinga's characteristics of play: 'play is not «ordinary» or «real» life. It is rather stepping out of «real» life into a temporary sphere of activity with a disposition all of its own' (Huizinga 1955: 8).

If virtuality and play have much in common, or are even two sides of the same coin, then Huizinga's claim about the non-moral character of play will hold for the virtual as well. If this is true, a lot of issues dealt with in cyberethics seem not to be ethical issues at all. The ethical dimensions of, for instance, computer games will under such circumstances be a non-theme.

This paper poses and tries thus to answer these questions:

1 Is play ethically neutral?

2 Are play and virtuality/virtual worlds relevantly similar, so that an answer to the first question will also be an answer to the question of the ethical neutrality of virtuality?

For the Huizinga claim to be addressed towards cyberethics, the connections between play and virtuality must be sufficiently strong (question 2). I will present some important writers' views on play - among them, of course, Huizinga. Then, I will compare these views or characteristics on play, firstly on the level of concepts and secondly with some examples of entities in cyberspace to see whether they can be considered to be play. Finally, I will take up a definite play-like activity in cyberspace, virtual worlds, and a much debated ethical question there, namely virtual rape, to see whether these constitute a counter-argument to Huizinga's claim of the ethical neutrality of play.

\section{Play and virtuality: initial definitions}

On both play and virtuality, it is hard to find consensus about definitions. Kooij claims that contemporary play research faces two great problems. The first problem is the multitude of play theories, which have not merged into one general theory. The second, and related, problem is that there is 'a kind of scientific war within social sciences ... between advocates of the nomothetical, quantitative approaches, and the hermeneutic, qualitative 
methods' (Kooij 2007: 14). This makes comparison between the two slightly awkward. However, inclusive characteristics of both will make the comparison plausible.

What about the distinctions between 'game' and 'play'? Are they synonyms, or is 'game' a subclass of 'play'? This is a difficult topic. Translations of 'play' and 'game' between Germanic languages are not straightforward. The matrix below shows how English, German and Norwegian languages differ in which phenomena are included in the meaning of each word.

\begin{tabular}{|l|l|l|l|l|}
\hline & $\begin{array}{c}\text { Game with } \\
\text { distinct } \\
\text { rules }\end{array}$ & $\begin{array}{l}\text { Performing } \\
\text { music }\end{array}$ & $\begin{array}{l}\text { Performing } \\
\text { a character } \\
\text { on stage }\end{array}$ & $\begin{array}{c}\text { Children's } \\
\text { play }\end{array}$ \\
\hline English & Game & Play & Act & Play \\
\hline German & Spiel & Spiel & (Schau)spiel & Spiel \\
\hline Norwegian & Spill & Spill & (Skue)spill & Lek \\
\hline
\end{tabular}

At this stage, we will let 'game' be a subclass of 'play', but come back to the question after having discussed what we mean by 'play'.

\section{Virtuality}

The following is a brief overview of some significant writers' characterizations of the virtual:

- Gilles Deleuze: An aspect of reality that is not material, but which is nonetheless real. (Wikipedia 2009)

- Jarin Lanier: For something to be virtual it has to be indistinguishable [from the actual entity] in some practical context, while it remains distinguishable in another' (Søraker 2009a: slide 3)

- Michael Heim: Simulation, artificiality, interaction (Heim 1993: 109111)

- Johnny Søraker: Virtual: Interactive computer-simulation (Søraker 2009a: slide 4)

Søraker includes 'computer' because his topic was virtuality in computermediated virtual worlds. In order to compare virtuality with a phenomenon that Huizinga regards as very ancient, indeed observed by animals as well, we have to make a difference between the technical framework, or context, and the activity in which virtuality takes place. Technology gives 
new opportunities to 'some' activities and the question here is whether this 'some' refers to plays.

\section{Play}

Let us next look at some characteristics of $\mathrm{play}^{2}$, starting with Huizinga.

\section{Huizinga}

At the start of Homo Ludens, Huizinga describes three main characteristics of play. The first is that 'all play is a voluntary activity' (Huizinga 1955: 7). Play 'is free, is in fact freedom' (Huizinga 1955: 8). With a view towards our thematic focus on virtuality, the second characteristic is especially interesting:

A second characteristic is closely connected with this [freedom], namely, that play is not 'ordinary' or 'real' life. It is rather stepping out of 'real' life into a temporary sphere of activity with a disposition all of its own. (Huizinga 1955: 8)

The temporal aspect of play is for Huizinga so important that he calls it the third main characteristic:

Play is distinct from 'ordinary' life both as to locality and duration. This is the third main characteristic of play: its seclusion, its limitedness. It is 'played out' within certain limits of time and place. (Huizinga 1955: 9)

In connection to this spatial limitedness, or playground, he claims that play 'creates order, is order' (Huizinga 1955: 10). To summarize, Huizinga's view is that play has its own domain in space and time with its imbedded order, that participating is free and voluntary and that play is not 'real' life. Huizinga's method in the subsequent chapters in Homo Ludens is to use these characteristics to examine various elements of human culture and point out the play aspects in each of them: law and jurisdiction, warfare, science, poetry, politics, philosophy, and art. I will use the same method on virtuality in cyberspace, but let us first look at what some other writers have identified as characteristics of play.

\section{Bateson}

The anthropologist and cyberneticist Gregory Bateson wrote an important article in 1955 titled 'Play signals and meta-communication'. He observed two young monkeys in a zoo fighting in a playful way. They exchanged some signals to each other 'which would carry the message «this is play»" 
(Bateson 1976: 120). The signals meant that their combat was not real combat, just play. Bateson developed a meta-communicative theory in which the players 'know that the play episodes are not real; they are only reproductions of life' (Saracho \& Spodek 2003: 9). The players exchange signals indicating 'These actions in which we now engage do not denote what those actions for which they stand would denote' (Bateson 1976: 121). Bateson calls this his 'expanded definition of play' (Bateson 1976: 121). This playing context, or 'own domain in space and time' in Huizinga's framework, is fragile. If the meta-communication is misunderstood or deliberately broken, the context of play vanishes, and the fragile distinction between primary processes (the meaning of a signal) and secondary processes (the signalled meaning of a signal) collapses. Even small children have accidentally killed their playmate during something that started as play (Selmer-Olsen 1995: 133).

Bateson's meta-communication is close to Huizinga's 'not real life' and is a way to establish the play domain. The fragility of this domain is to be observed.

\section{Bishop}

In his book Mathematical Enculturation, Alan Bishop claims that there are 'six key «universal» activities [that] are the foundations for the development of mathematics in culture' (Bishop 1988: 59). The first four are measuring, counting, locating, and designing. Of the two last, he writes:

The two which I shall argue are mathematically very important for that purpose are playing and explaining. Playing is concerned with social procedures and rules of performance, and also stimulates the «as if» feature of imagined and hypothetical behaviour. (Bishop 1988: 23)

Even if play is free and voluntary, it may also be connected with strict rules, such as with various games. The ' "as if» feature' is an important ability when it comes to new ideas, and is therefore highly valuated as a mathematical activity. This is closely linked to what Bishop classifies as 'modelling of reality' and 'abstracting from reality certain forms and structures' (Bishop 1988: 45). He also thinks that a lot of games can be traced back to such reality modelling. According to Bishop, an important aspect of playing is that the 'real/not real boundary is well established' (Bishop 1988: 43). To take part in play, players have to agree to 'not to behave "normally»' (Bishop 1988: 43). The context of playing itself implies that a new set of rules and 'realities' is established. In this respect, Huizinga's claim about being beyond vice and virtue can be supported if vice and virtue are restricted to 'normal' realities only. An opposition to this would be to claim that a new set of play rules just 
implies a new body of ethics suitable for that specific play - not suspension of ethics altogether.

I summarize Bishop's understanding as follows: play is a kind of existence between reality and the unreal where the real part is trying to model reality and the part beyond reality is the 'as if' way of acting or thinking.

\section{Gadamer}

Hans-Georg Gadamer has a whole chapter (Part 1, II, 1, A) on play in his famous Wahrheit und Methode (Truth and Method). Play is something that plays the player: 'all playing is a being-played' (Gadamer 1989: 106). The player is absorbed by the play, but not in a way that the play can do anything with the player. The player knows that 'what he is doing is "only a game»" (Gadamer 1989: 102). The playing field (Spielraum), defined by the play itself by its structure (Gadamer 1989: 107), sets the boundaries for the play (thereby creating a structure similar to Huizinga's play domain). In this respect, there is a kind of freedom and ease in play, not in a way that it does not require an effort to play, but that 'refers phenomenologically only to the absence of strain' (Gadamer 1989: 105).

'First and foremost, play is self-presentation', Gadamer writes on page 108. Play is an end in itself. This is, however, not an obstacle to using a play or game as representation. Indeed, 'all presentation is potentially a representation for someone' (Gadamer 1989: 108). Gadamer mention religious rites, plays performed in a theatre and children playing cars as examples of representations. This fits well with both Bishop's 'as if' mode of play and Bateson's meta-communication theory: actions which do not denote what those actions for which they stand would denote.

From this paper's perspective, it is interesting to note that Kjetil Steinsholt uses the word 'virtual' in his interpretation of Gadamer:

The important thing in play is its 'virtual world', or the playing field it creates. It is the play itself, and not our thoughts, which decides the reality of play. The player who devotes himself in play will experience play as an 'unsurpassable reality'. (Steinsholt 1999: 146, my translation)

To summarize, Gadamer's understanding (and Steinsholt's interpretation) is that the player is played with by the play and is thus absorbed by the play in the virtual world that the play creates. The play is self-presentation, but can also function as representation.

In order to become updated in the study of play, I was advised by a professor of pedagogy to read the book Contemporary Perspectives on Play in Early Childhood Education by Saracho and Spodek. A chapter on contemporary theories gave me the impression, however, that no considerable progress has been made in recent decades. The researchers themselves asked 
questions such as 'what-else-is new?' and 'so-what?' (Saracho \& Spodek 2003: 11). What is considered interesting is 'research on pretending, perspective taking, and mental states' (Saracho \& Spodek 2003: 11). These topics are mostly nothing but various aspects of what we have learned from Huizinga, Bateson, Bishop, and Gadamer already, notably aspects of 'as if'. Both perspective taking and pretending are examples of our acting 'as if' we are something or someone else.

What is new, however, since the time of Huizinga and Bateson, are computer games. This new arena for playing, either alone or connected with others through an electronic network, is evaluated to have both positive and negative consequences. Lee and Peng review literature on the psychological and social effects of computer games. The tendency is that violent entertainment games have negative effects on, for instance, empathy towards others, heart rate, blood pressure, prosocial behaviour, and aggression. Even non-violent entertainment games may result in addiction and game dependency, gender stereotyping and physical health problems on the negative side; on the positive side, however, they may also contribute to training, sociability, academic performance, therapy, spatial visualization, and cognitive abilities. Educational games seem to lead to only positive effects (Lee \& Peng 2006: 328). Lee and Peng show that the amount of research on contents of games is much greater than on media form. To understand game effects, however, both aspects are important (Lee \& Peng 2006: 340). Sandra Calvert has a mainly positive attitude to the effects of computer games, and claims that it has been difficult to establish evidence of erosion of verbal skills, whereas it appears that video game play cultivates the development of visual spatial skills' (Calvert 2005: 128).

With this short look into research on computer games, we are much closer to making a bridge between playing and virtuality. But first, we have to go back to the question about 'play' and 'game.' By 'game', we usually understand some kind of activity regulated by a set of rules or framework which has to be followed for the game to be successful. This does not fit with Huizinga's first aspect of play, namely that play is absolute freedom. Bishop, on the other hand, mentions that following strict rules is some aspect of playing. Indeed, one can 'save' the freedom of play in games by focusing on two aspects of games: 1) the game constructor is free to make whatever rule is appropriate for the game to function; 2) playing a game (note the emphasis) is an option based on freedom. When people participate in a game out of duty and not by free will, they are seldom enthusiastic players and often make negative contributions to the game, and in some cases even spoil the game. Note also the choice of wording here. We always talk of 'playing a game', not 'gaming a game', which in itself indicates a close relation between the two concepts. Games and play have in common representational and asif aspects. Games are often some kind of models of the real world or a fic- 
tional world, and the various players are represented by something in the game, such as a figure or avatar (in computer games). Sport is a kind of game that may be considered otherwise. There is no representation between player and what happens in the game. The actors (sportsmen) act themselves and with their own abilities, often with great seriousness involved. The rule aspect is, however, present. Furthermore, as with other kinds of games, one can say about a sport event that it is merely a game'. Doing so is to say that it is something beyond or outside 'normality', i.e. our normal, actual life and realities.

For our purpose, we can omit sport from the further discussion since it is play versus virtuality, with examples from computer games, which are used to discuss the eventual ethical aspects of play. If sport is not play, then it cannot either be used in the discussion about play and virtuality. So, when speaking about 'game' hereafter, it is understood as a subclass of 'play'.

\section{Is virtuality play?}

So, playing a computer game is to play. Gadamer's description of the play that plays the player is to the point regarding what happens with the players at the Gathering in Hamar and in similar settings. The domain perspective of Huizinga is also clearly present at such gatherings. The computer itself is a distinct domain for computer games. As soon as one removes oneself from the computer or when the computer program is shut down, the play ends. What is more interesting is to see whether there are connections between play and virtual life in cyberspace elsewhere.

Both Lanier and Deluze say that the virtual is something between reality and non-reality. For Deluze, it is the materiality that differs between real and not real. One might say that cyberspace is material in the sense that physical machines are required. These are, however, mere tools which themselves 'want' to be as transparent as possible. It is what is mediated through the flickering dots on a screen and through a computer's loudspeakers that is virtuality - and possibly also play.

Let us examine the materiality characteristic from another point of view. Everyone has noticed that a child can make almost anything into whatever he or she wishes by the 'as if' act. A stick can be a sword or a gun. A pine cone can be a cow and a horse. I still remember when I was bicycling in front of a brass band that was rehearsing in the street, and pretending to drive a police car making way for the brass band on our National Day. For me, there was a material difference between my bicycle and the police car. This example also fits well with Lanier's description of virtuality, since the difference between a bicycle and a car is not fundamental. They are both vehicles, and to paraphrase Lanier, the two must be indistinguishable in 
some practical context', while they remain 'distinguishable in another'. This short story from my youth is also a good example of simulation (cf. Heim 1992), where I simulated driving a police car by cycling my bicycle. I suppose a lot of children simulate driving cars or motorcycles when using their bicycles as well.

However, I have so far just given examples of how play can be described as virtual. It is the converse that is the most interesting in this paper. Let us look at Facebook and other similar activities on the Internet. The play factor on Facebook and similar social networking sites is probably lower than on Second Life and other virtual worlds, but this does not imply that playing does not happen on Facebook. In fact, as I will argue, the uncertainty of whether one is playing or not is in itself a challenge.

On Facebook and discussions boards, especially those with high levels of activity and which are committed to a specific topic where discussions are dominated by a rather stable group of participants, people can at least from time to time behave in play-like ways. The presence of a playing domain is obvious, as is for all computerized activity (as mentioned above). The participation is free and voluntary (cf. Huizinga 1955). It is not real life in the sense that it is electronically mediated and disembodied. The 'as if' element needs, however, closer examination. Many people involved in these arenas participate with their own true identity, as in the case of Facebook. In discussion boards, however, it has been rather common to have an avatar and a nickname, which may disguise one's true identity. This is definitely the case for virtual worlds such as Second Life. Using an avatar is indeed an 'as if' element. People may also use a nickname or username that seems like an ordinary name and thus pretend to be an identifiable person. Often, the participants cannot be sure whether a user is himself or herself or just acts like one. The 'as if' aspect is then an option or possibility in such arenas, which users must take into consideration. Does a user actually have the thoughts, values and attitudes, which are uttered, or is he or she 'just playing', pretending to be another than what he or she really is? When someone on the same 'physical' playing field is playing while some others are not, this creates confusion, especially when the knowledge of whether one actor is playing or not is blurred.

\section{Amoral domains?}

The initial question concerned the validity of Huizinga's claim: 'Although it is a non-material [mental] activity it has no moral function. The valuations of vice and virtue do not apply here' (Huizinga 1955: 6). We have seen that many of the virtual activities that take place in cyberspace are either pure games and are thus play, or have strong play-like elements. To challenge 
Huizinga's claim, let us examine a case, the so-called 'first virtual rape' (Søraker 2009b) from the virtual community LambdaMOO, which was a text-based multiplayer computer game.

The case is described by Julian Dibbell who was a rather new participant in the LambdaMOO community and watched the incident from the sidelines. The event happened in 1993, and at that time virtual worlds were merely text based. A database was 'running' the game and the users participated through avatars, which were virtual identities which the users had constructed themselves. To understand the context, let Dibbell explain it in his own words:

When users log in to LambdaMOO, for instance, the program immediately presents them with a brief textual description of one of the rooms of the database's fictional mansion (the coat closet, say). If the user wants to leave this room, she can enter a command to move in a particular direction and the database will replace the original description with a new one corresponding to the room located in the direction she chose. When the new description scrolls across the user's screen it lists not only the fixed features of the room but all its contents at that moment-including things (tools, toys, weapons) and other users (each represented as a 'character' over which the user has sole control). (Dibbell 1998: 14)

'Sole control' seems to be true with some exceptions, since on this occasion one of the avatars, Mr Bungle, had made a tool or weapon, a voodoo doll to force one of the room's occupants to sexually service him in a variety of more or less conventional ways' (Dibbell 1998: 13). Mr. Bungle used the voodoo doll on four female-like avatars, until he was stopped by 'a wise and trusted old-timer who brought with him a gun ... that ... enveloped its targets in a cage impermeable even to a voodoo doll's powers' (Dibbell 1998: 13). The whole scene was watched by the others avatars in the same virtual room, and was to be much debated in the days to come on a 'mailing list called «social-issues»' (Dibbell 1998: 15). One of the victims demanded virtual castration of $\mathrm{Mr}$ Bungle. Two days afterwards she strengthened her request and asked for virtual death penalty:

I am requesting that Mr. Bungle be toaded ${ }^{3}$ for raping Moondreamer and I. I have never done this before, and have thought about it for days. He hurt us both. (Dibbell 1998: 17)

On the third day after the rape, the LambdaMOO community gathered to a kind of court proceeding, but failed to come to an agreement. One of the wizards ${ }^{4}$ made a decision based on what seemed to be the general mood in the community, and 'toaded' (executed) Mr Bungle. Some days later, however, Mr Bungle is supposed to have reincarnated himself into Dr Jest (Dibbell 1998: 25). 
Why bother? This was just a game and no actual rape of a person's body had taken place. The incident was merely text on screens. These texts were, however, sufficient to make mental pictures and mental experiences in accordance with the 'as if' ability. One has to know what an avatar is to understand why the victims of Mr Bungle's voodoo used the word 'rape'. Søraker, commenting the same case, puts it this way:

In order to understand how such actions can be interpreted as equivalent to rape, keep in mind that some individuals dedicate the majority of their social life to online role playing, that they have invested many years in creating a consistent, trustworthy and virtuous character in order to overcome the lack of physical presence, and that all of those efforts can be annihilated by one single instance of having one's avatar commit the unspeakable acts in question. Keep also in mind that these forced acts are witnessed by your closest friends and that there is often no way in which to submit proof that you were in fact under the control of someone else. Your name is damaged for always, trust and friendships dissolve, feelings of shame, humiliation and lost autonomy ensue. (Søraker 2009b: 23)

This game had become a very serious game. What is real and what is fictitious does not follow the embodied-disembodied distinction. The virtual reality is definitely a reality of its own, which can harm people and be enjoyed by them in similar ways that embodied experiences can. Alternatively, to cite Dibbell's reflections on the Mr Bungle case: 'Since rape can occur without any physical pain or damage, I found myself reasoning, then it must be classed as a crime against the mind' (Dibbell 1998: 26).

Was the virtual rape really play? It was play in the sense that it fits with many of the play characteristics given by Huizinga, Bishop and Gadamer. It had its own domain (Huizinga), it was not 'real' life (Huizinga), and the initial participation was free and voluntary (Huizinga). The rape itself was modelled on reality (Bishop) (otherwise it would not be termed 'virtual rape'), and the 'as if' mode (Bishop) was in action to enable it to be experienced it as rape. Finally, the victims were played by the play and absorbed by it (Gadamer). Bateson's characteristic of meta-communication is, however, interesting to examine more closely. The actions with the voodoo doll did in fact stand for what they denoted, and that was why the incident was regarded as virtual rape. Using Bateson's argument in this case, the actions with the voodoo doll should not have stood for what they denoted. Thus, there was a breakdown of the meta-communication. This is closely connected with the fragility of the play, and it seems that violating this meta-communication is precisely what destroys something that in all other respects has the characteristics of being a play. Playing rape with text on a computer screen seems to break down into mental rape because rape is more that something that happens with the body. Søraker argues that rape is, in principle, harder to determine as violence than, for example, murder, since if we do not consider the mindset and consent of the parties involved, 
there is in some cases no way in which to ascertain whether it is rape or not' (Søraker 2009b: 24). He argues further than since rape is partly minddependent, it can also be reproduced in virtual worlds.

Huizinga's claim about the amorality of the play may be true if we believe that play stops when it becomes immoral or involves immorality. Bateson's characteristic of meta-communication and the fragility of play make this distinction possible.

After a tragic death in 1994 of a child killed by another child at a playground in Trondheim, Norway, the concept of 'evil play' was brought forward in a partly tabloid debate that followed. Central in this debate was an essay with the same title ('Den onde leg' [The evil play]) by the Danish psychologist Ivy Schousboe, which she concludes by complaining that few researchers are interested in children's 'possible anti-social competences' (Schousboe 1993: 118, my translation), probably due to our culture's need of sustaining the myth of the innocent child. As a reflection on this accident and debate, the child researcher Selmer-Olsen argues that the relevance of the question about 'play being good or evil, [is] like the question about life being good or evil' (Selmer-Olsen 1995: 133, my translation).

Using the thoughts of Huizinga and Bateson referred to earlier in this paper, may lead to the conclusion that when play becomes evil it ceases to be play. This could also be said of the virtual rape case insofar as what happened until the rape took place was 'just a computer game' and that the game or play was ended by that incident. This interpretation is problematic if we insist on a similarity between play and the virtual, since the virtuality did not end when the rape started. It was within a virtual setting that the incident regarded as rape took place. Moreover, it is exactly because it was both within a virtual setting and also because it was a game that one could argue that the 'rape' was not a problem because it was 'just a game'. The argument for regarding the rape as being outside the domain of play is thus based on the opposite claim that it happened inside the domain of play. The amorality of playing (and virtuality) thus seems difficult to sustain.

Consider another reflection on Huizinga's claim. It is a rather common (but not necessarily true) opinion that technology in itself is beyond ethics, that the technological machinery or tool is ethically neutral: 'Technology itself is incapable of possessing moral or ethical qualities, since «technology» is merely tool-making' (Ethics on Technology, 2009). It seems that Huizinga is making a similar statement: play in itself is ethically neutral. The above discussion about virtual rape may be taken as an example of how this virtual game truly could be used in an evil way, but that the game in itself could remain ethically neutral.

An argument against this is that there is a difference between a tool and play. A tool and technological apparatus is a thing, an object, whereas play is not an object but action(s) and a setting, a playing field. To play is a men- 
tal action, according to Huizinga. If play is action and ethics is about the moral qualities of actions, how is it possible to consider play to be outside morality? Are there ethically-neutral actions? Hardly! Reconsider the argument above, where Bateson's characteristic 'saved' play to be outside ethical questions until the fragility ends the play. Instead of letting the breakdown of the play be the distinction between amoral play and destroyed play, it can also be judged as the distinction between good and evil play. To play can indeed be a good action and an utterly preferable one, not 'only' a neutral one.

\section{Answering the initial questions}

We have concluded that play can hardly be regarded as a phenomenon outside the ethical domain just because play is action, and assessment of actions is partly what ethics is all about. This is supported by two examples where play and game were involved, one outside virtual worlds and one inside.

The second question about the similarity between play and virtuality is to some (great?) extent made plausible and using characteristics of play may be useful for a better understanding of virtuality. The similarity is obvious insofar as playing games is an important part of virtual worlds. Consider also that play is both actions and a setting, a playing field. It has no end outside itself. Play is self-presentation (Gadamer 1989: 108). The technology to support virtual worlds constitutes a playing field. To a lot of users, the computer technology is in itself an end, and the mere existence of programs (playing field) and activities (play) that make virtual worlds possible, are an example of this self-presentation of virtuality. When this takes place, virtuality and play blend together completely. They do so within the ethical domain, as argued in the above paragraph. So there is no such thing as an ethical 'free lunch'.

\section{Epilogue}

Play has often a ubiquitous character. This comes from the as-if aspect where play is simultaneously present and distant, embodied and disembodied, and involves myself and anyone. This is in accordance with Ole F. Lillemyr's aspects of play, partly borrowed from Joseph Levy: 'It is typical that the child puts aside reality' and that the player has an 'inner base for control' (Lillemyr 2004: 41, my translations). Play is seldom hampered by restrictions in time or place, but can happen under the most various conditions. 
The contemporary ubiquitous mobile computer are often packed with games, and can thus be interpreted as a quite natural extension of the ubiquitous play that can take a person everywhere and at the same time has its base and foundation in a physical reality situated by means of the user's body and may be used as a toy as well. The mobile computer is thus the toy, which not only mentally takes the user wherever in an as-if play, but to some extent also actually everywhere insofar that it has an Internet connection to bring nearly every Internet connection who is able to bring information from nearly everywhere to one's screen, and to imaginary worlds in cyberspace as well.

The mobile and ubiquitous computer, whether it is an Internet-connected smartphone, a mini-PC or a laptop, is in itself technically and physically at hand everywhere in our culture. Nearly everyone in the Western world has access to one and can be connected to the rest of the world almost everywhere. Such devices offer their users worldwide access electronically and reach the user by the ordinary senses, more or less as if they were out there. This is a type of concrete ubiquity which differs from the ubiquity of play because it is not purely mental, but material both in terms of means (technology) and content. The messages are brought to us by pictures on a screen and sound from a speaker. A critical question regarding this new situation could be whether this technical ubiquity will replace the ubiquity of play, or just be a new platform from which new kinds of as-if plays take place?

David Rotheberg's model of technology is that it is always 'at hand's end', an extension of our hands (Rothenberg 1993). Piaget said the same about symbolic play. According to Kooij, the play in Piaget's view 'can bridge over distances - words can reach further than hands' (Kooij 2007: 15). Accordingly, the play and technology have in common that they both extend our horizon and playground - the first mentally, and the second materially. However, man has always been able to use material technology for mental purposes, whether invented for those purposes or not. To believe that computer games on mobile computers could ever replace and destroy genuine play does not seem very likely. Play is always contextual in the sense that it uses the material reality at hand and plays further on it. Play is not restricted upon it more than as a starting point; it can always fly away. If we are to believe Alan Bishop, it is exactly this playful attitude to reality which also is a condition for all mathematical development (Bishop 1988: 46), which in turn is a basis for science and technological exploration. The ubiquitous mobile computer, that in itself offers ubiquity, is in reality a product of man's ability to play and to imagine the non-existing as if it exists. 


\section{Notes}

1 The translation 'non-material' is slightly misleading. The corresponding German word is geistig (Huizinga 1939: 10) (the English translation was derived from an German translation) and the Dutch original text has geest (Huizinga 1938/1950/2007: 34). Geistig/geest is a narrower concept than 'non-material'. Instead, I will use the word 'mental' in this paper when I refer to this quote by Huizinga.

2 The literature on play is very large. Only a few important examples can be given in this paper. One aspect that is omitted here is 'to explain play as the experience of «flow»" (Frost, Wortham \& Reifel 2001: 96), an idea taken from the psychologist M. Csikszentmihalyi (Csikszentmihalyi 1979).

3 'Toaded' means to be made a toad. The phrase comes from another game and implies the erasure of a player's descriptions and attributes which are replaced by those of a toad. The effect is that the user account and its content is deleted.

4 A wizard is a kind of moderator or webmaster.

\section{Literature}

Bateson, G. (1976) A theory of play and fantasy. In Play - Its role in development and evolution, eds. J.S. Bruner, A. Jolly \& K. Sylva, pp. 119-129. Harmondsworth: Penguin Books.

Bishop, A.J. (1988) Mathematical enculturation: A cultural perspective on mathematics education. Dordrecht: Kluwer.

Calvert, S.L. (2005) Cognitive effects of video games. In Handbook of computer games studies, eds. J. Raessens \& J. Goldstein, pp. 125-131. Cambridge, MA: The MIT Press.

Csikszentmihalyi, M. (1979) The concept of flow in play. In Play and Learning, ed. B. Sutton-Smith, pp. 257-274. New York, NY: Gardner Press.

Dibbell, J. (2007) My tiny life: Crime and passion in a virtual world. 2nd Ed. Retrieved 13 April 2009 from http://www.lulu.com/items/volume_63/1 070 000/1 070 691/3/print/1 070 691.pdf. (1st edition Henry Holt 1998.)

Ethics of Technology. (2009) Wikipedia. Retrieved 14 April 2009 from http:// en.wikipedia.org/wiki/Ethics_of_technology

Frost, J.L., Wortham, S.C. \& Reifel, S. (2001) Play and child development. Upper Saddle River, NJ: Merrill Prentice Hall.

Gadamer, H.-G. (1989) Truth and method. London: Sheed \& Ward.

Heim, M. (1993) The metaphysics of virtual reality. New York, NY: Oxford University Press.

Huizinga, J. (1938/1950/2007) Homo ludens, Proeve eener bepaling van het spelelement der cultuur. Retrieved 5 May 2009 from http://www.dbnl.org/tekst/ huiz003homo01_01/index.htm (Original published by H.D. Tjeenk Willink \& Zoon, Haarlem, 1950, pp. 26-246)

Huizinga, J. (1939) Homo ludens: Versuch einer Bestimmung des Spielelementes der Kultur. Amsterdam: Pantheon.

Huizinga, J. (1955) Homo ludens: A study of the play-element in culture. Boston: Beacon Press. 
Kooij, R.v.d. (2007) Play in retro- and perspective. In Several perspectives on children's play, eds. T. Jambor \& J.v. Gils, pp. 11-27). Antwerpen: Garant.

Lee, M.K. \& Peng, W. (2006) What do we know about social and psychological effects of computer games? A comprehensive review of the current literature. In Playing video games. Motives, responses, and consequences, eds. P. Vorderer \& J. Bryant, pp. 327-345. Makwah, NJ, \& London: Lawrence Erlbaum.

Lillemyr, O.F. (2004) Lek, opplevelse, loering: I barnehage og skole. Oslo: Universitetsforlaget.

Rothenberg, D. (1993) Hand's end: Technology and the limits of nature. Berkeley, CA: University of California Press.

Saracho, O.N. \& Spodek, B. (2003) Understanding play and its theories. In Contemporary perspectives on play in early childhood education, eds. O.N. Saracho \& B. Spodek, pp. 1-19. Greenwich, CT: Information Age Publishing.

Schousboe, I. (1993) Den onde leg. En udvidet synsvinkel på legen og dens funktioner. Nordisk Psykologi, 45 (2), pp. 97-119.

Selmer-Olsen, I. (1995) Det unyttiges nødvendighet. Barn. Nytt fra forskning om barn, 3, 131-142.

Steinsholt, K. (1999) Lett som en lek? Ulike veivalg inn i leken og representasjonenes verden. Trondheim: Tapir Forlag.

Søraker, J.H. (2009a) Introduction to philosophy of virtuality. Paper presented at the Philosophy of Virtuality, March 9th 2009, Trondheim.

Søraker, J.H. (2009b) The neglect of reason. A plea for rationalist accounts of the effects of virtual violence. In Emerging ethical issues of life in virtual worlds, eds. C. Wankel \& S. Malleck, pp. 15-32. Charlotte, NC: Information age Publishing.

Wikipedia. (2009) Virtual. Retrieved 2 April 2009 from http://en.wikipedia.org/ wiki/Virtual 